\title{
The Attrition and Migration Behaviour among Hungarian Radiographers
}

\author{
David Sipos $^{1,4}$, Csaba Vandulek ${ }^{1}$, Melinda Cs. Petone ${ }^{1}$, Andras Kedves ${ }^{1}$, Attila A. Pandur ${ }^{3}$, Imre Boncz ${ }^{2}$, \\ Jozsef Betlehem ${ }^{3}$, Imre Repa ${ }^{4} \&$ Arpad Kovacs ${ }^{1,4}$ \\ ${ }^{1}$ Faculty of Health Sciences, Dept.of Diagnostic Imaging, University of Pecs, Pecs, Hungary \\ ${ }^{2}$ Faculty of Health Sciences, Institute of Health Insurance, University of Pecs, Pecs, Hungary \\ ${ }^{3}$ Faculty of Health Sciences, Institute of Emergency Care and Pedagogy, University of Pecs, Pecs, Hungary \\ ${ }^{4}$ Faculty of Health Sciences, Doctoral School of Health Sciences, University of Pecs, Pecs, Hungary \\ Correspondence: Arpad Kovacs, University of Pécs, Faculty of Health Sciences, Szent Imre street 14/B, Kaposvár, \\ Pecs 7400, Hungary. Tel: 36-8250-2050. E-mail: kovacs.arpad1979@gmail.com
}

Received: July 21, 2017 Accepted: October 11, 2017 Online Published: November 20, 2017

doi:10.5539/gjhs.v10n1p1 URL: https://doi.org/10.5539/gjhs.v10n1p1

\begin{abstract}
Introduction: Organizations are social systems where human resources are the most important factors. In recent years, healthcare employers have assigned a high priority to the recruitment of educated health professionals. The aim of our study was to identify the possible reasons behind the migration and attrition behaviour among Hungarian radiographers. We were interested whether the professional staff have ideas across borders which can be connected with attrition.
\end{abstract}

Material and Methods: In our cross-sectional retrospective study we used a self designed questionnaire and the Effort-Reward Imbalance (ERI) Questionnaire's shortened version. Our target group were active radiographers with BSC radiography degree. The study sample counted 216 radiographers $(n=216)$. For data analysis we used the SPSS 13.0. Variance analysis, paired sample T-test, Chi-square test, linear regression and descriptive statistics were used with the performed probability of $95 \%(\mathrm{p}<0.05)$.

Results: $30.6 \%$ of responders $(n=66)$ were considering working abroad, $40.3 \%(n=87)$ of responders remain in Hungary. At the age group of 20-30 we can observe significant relationship between the working opportunity abroad $(\mathrm{p}=0.001)$. The migration tendency was specific for radiographers with no children $(n=54)$. We found a significant relationship between the working ability abroad and the radiographers' years spent working in the healthcare system $(p=0.008) .41 .7 \%$ of respondents $(n=90)$ think that it would be a favorable option to making a career change. We also found a significant relationship between the possibility of working abroad and the desire for higher wages and the lack of making career advancements as a radiographer $(\mathrm{p}=0.001 ; \mathrm{p}=0.001)$.

Conclusion: Correlation of our results with similar research was difficult because very few researchers put their interest into radiographers. In respect to other healthcare workers (eg.: nurses, physiotherapists) our result correlate well with the literature. Our research provides a broad view of the migration and attrition tendency among Hungarian radiographers and its underlying causes. According to our study changes should be implemented in the Hungarian system to keep the younger radiographers home.

Keywords: migration, attrition, radiographer

\section{Introduction}

In recent years, healthcare employers have assigned a high priority to the recruitment of educated health professionals. The analysis of international migration is a heterogenous field, fragmented by disciplinary boundaries and differing levels of analysis. The creation of border free Europe endowed the healthcare professionals to relocate their workplace all over Europe (Dummond, 2007; Suciu et al., 2017). Most studies focused on the actual workplace experience of principally uneducated employee (Ross \& Polsky, 2005; Lowe \& Duan-Rung, 2016). Studies that are not restricted to the health sector spotlight on the workplace and recognize that immigration status reputate migrants sense of occupation susceptibility (Kingma, 2001). Radiographers encounter numerous stressors during their activities and those activities influence their personal and professional life. These 
factors which are connected to stress are related to control over work, relationships, workplace, and the organization as well (Grönroos \& Pajukari, 2007). Institutions are social systems where personnel are the most important factors. If the human resourcement is not satisfied, it may affect effectiveness and efficiency (Lok \& Crawford, 2003). Institutions will be closed without employees efforts. Employees' dedication towards their jobs and commitment to their organizations have been shown to be the prime elements of organizational capability (Chang, 2006). Job satisfaction, commitment and the opportunity to move up in the organisation are essential to retaining and attracting well-qualified personnel (Mosadeghrad et al., 2011). Healthcare personnel who are qualified and experienced in the field seemed to be more ambitious, tenacious and were more capable of development than unqualified health workers (Ramesh, 2013). If the workers of the intitutions experience job satisfaction, they will become more productive with less of a chance to attrition (Piko, 2006). The dissatisfaction of the employee' may affect on intention to leave as well as turnover and burnout (Allen \& Mellos, 2002; Burisch, 2002). Employees' job satisfaction is also found to be positively related to patient satisfaction at every branch in healthcare (Lima et al., 2006). The satisfaction level of healthcare workers has been studied different view points and different tools such as from manager's side and from the level of the diagnostic equipments. Personal characteristics, age, gender, salary, family status, years spent in the healthcare system and demographic variables are also associated with the satisfaction level of the personnel (Smith, 2002; Beitzel et al., 2011). Job satisfaction, organizational commitment and high level of health equipments are important singals to managers because of the desire to retain a stable and determined workforce. For younger generation is much more satisfying to work with the newest innovations (Makowiec-Dabroswska et al., 2008). Satisfaction is also a defenition if the personnel like or dislike their jobs. It's value is based on the outcomes and desired outcomes of the expectations. Maintaining supportive and positive working environment makes for the healthcare staff remain in the healthcare system (von Vultee et al., 2007).

There is a small number of research studies in the literature that have examined the associations between the attrition and migration behaviour among radiographers, even among radiology department workers. This study aims to overcome this by focusing on the possible reasons behind the migration and attrition behaviour among Hungarian radiographers. We were interested whether the professional staff have concrete ideas as how, why they want to quit their profession or their homeland. We were also interested how can be those factors connected with attrition and migration attitude as well.

\section{Material and Methods}

Our crossectional study was conducted between April 2016 and September 2016. For data collection we used our self designed questionnaire and the Effort-Reward Imbalance (ERI) Questionnaire's shortened version. All questions refer to the current occupation and subjects were asked to indicate how far the items reflect their work situation. In our self designed questionnaire we used 36 questions to get information about the radiographers. This included information on demographics, job satisfaction, migration and attrition. The questionnaire also contained questions to assess the possible reasons behind the migration and attrition behaviour. The reliability and validity of our self designed questionnaire is ensured by the inclusion that the questions were used in previous researches connecting to attrition and migration behaviour. In the ERI Questionnarie the radiographers were able to answer for six-six allegations at the reward and occupational work safety dimension; and three allegations concerned to the effort dimension. At the reward and at the occupational work safety dimension respondents were asked to evaulate the extent to which of these conditions produce strain, using a five-point rating scale. The options were the following: $0=$ "does not apply"; $1=$ does apply, but not strained"; $2=$ "does apply, but somewhat strained"; $3=$ "does apply and strained"; $4=$ "does apply and very stained". At the effort dimension respondents were asked to evaluate their attitude on a four-point rating scale like: $0=$ "strongly disagree", 1="disagree", 2="agree", $3=$ "strongly agree". The rating at the reward and at the occupational work safety dimension were defined with higher ratings pointing to higher efforts. Our target group were active workers with a BSC radiographer degree.

We sent out 440 questionnaires to selected radiology departments, radiology clinics, private health centers. 338 of the questionnaries were returned filled out. We excluded from our sample radiology workers without a university degree. Overall our sample counted 216 radiographers $(n=216)$.

For data analysis we used Statistical Package for the Social Sciences (SPSS) 13.0. The SPSS software was used to analyze the quantitative data which included descriptive and inferential statistics. We applied analysis of variance (ANOVA), paired sample T-test, Chi-square test, linear regression and descriptive statistics with the performed probability of $95 \%(\mathrm{p}<0.05)$. 


\section{Results}

\subsection{Sample Characterization According to Demographic and Educational Data}

Our sample included 216 radiographers $(n=216)$. Among the responders, $68 \%(n=147)$ were female and $32 \%$ $(\mathrm{n}=69)$ male. The participants ranged in age from 23 to 57 years with the average age of $32,22(\mathrm{SD}=7.402)$ years. For better characterization we divided our sample into three age groups: $20-30$ years old $(n=122), 31-40$ years old $(\mathrm{n}=62)$ and over 40 years $(\mathrm{n}=32)$. (Table 1$)$

Table 1. Description of the respondents

\begin{tabular}{|c|c|c|}
\hline Variable & & $\mathrm{N}=\mathbf{2 1 6}$ \\
\hline Age & Median & $32,22(23-57)(\mathrm{SD}=7,402)$ years \\
\hline \multirow{2}{*}{ Gender } & Male & $32 \%(\mathrm{n}=69)$ \\
\hline & Female & $68 \%(n=147)$ \\
\hline \multirow{3}{*}{ Age groups } & $20-30$ years & $56,5 \%(\mathrm{n}=122)$ \\
\hline & $31-40$ years & $28,7 \%(n=62)$ \\
\hline & above 40 years & $14,8 \%(\mathrm{n}=32)$ \\
\hline \multirow{4}{*}{ Inhabitancy } & County seat & $51,9 \%(\mathrm{n}=112)$ \\
\hline & Town & $24,5 \%(\mathrm{n}=53)$ \\
\hline & Capital city & $15,7 \%(n=34)$ \\
\hline & Village & $7,9 \%(n=17)$ \\
\hline \multirow{5}{*}{ Marital status } & Living with their spouse/ life partner & $33,8 \%(n=73)$ \\
\hline & Single & $31 \%(n=67)$ \\
\hline & Living with their spouse/life partner and children & $21,3 \%(n=46)$ \\
\hline & Living with other family member & $8,8 \%(\mathrm{n}=19)$ \\
\hline & Living with other person & $5,1 \%(\mathrm{n}=11)$ \\
\hline \multirow{3}{*}{ Current financial status } & Average & $73,1 \%(\mathrm{n}=158)$ \\
\hline & Above average & $18,5 \%(\mathrm{n}=40)$ \\
\hline & Below average & $8,3 \%(n=18)$ \\
\hline
\end{tabular}

The majority, $122(51.2 \%)$ of respondents lived in a county seat, the second most occupated place were towns whose counted $53(24.5 \%)$ of respondents. $34(15.7 \%)$ of respondents lived at the capital city and the least, 17 (7.9\%) lived at villages. $73(33.8 \%)$ of the respondents lived with their spouse/life partner and $67(31 \%)$ of respondents were single. $46(21.3 \%)$ lived with their children as well under one household. $19(8.8 \%)$ of respondents lived with other family memeber and $11(5.1 \%)$ lived with other person. According the current financial situation $158(73.1 \%)$ of the respondents stated their financial situation to be average, $40(18.5 \%)$ of respondents declared their financial situation above average and $18(8.3 \%)$ of respondents thought their financial situation to be below average.

At the time of our research $29,6 \%(\mathrm{n}=64)$ of respondents stated an other qualification in addition to radiography and $19 \%$ of the whole sample $(\mathrm{n}=41)$ had a second occupation. Only 9 radiographers in the sample had a postgraduate university degree and not a single radiographer had $\mathrm{PhD}$ qualification. $36 \%(\mathrm{n}=79)$ of the respondents percieved that they can not prevail in a foreign country with their current language skills.

$38.4 \%(n=83)$ of respondents worked at a county hospital, $27.8 \%(n=60)$ at a university clinics, $16.7 \%(n=36)$ at a private healthcare, $11.6 \%(\mathrm{n}=25)$ at a national institution, and $5.6 \%(\mathrm{n}=12)$ of respondents worked at an outpatient surgery. Among the radiographer profession it is not uncommon, that radiographers are working with more than one modality at the same insitution. Most $(\mathrm{n}=106)$ worked with Computer Tomography (CT) and Magnetic Resonance Imgaing (MRI) modalities. 33 worked in General Radiography, Ultrasound and Mammography. 28 worked in Radiation Oncology. 14 worked on Digital Subtraction Angiography (DSA) modality and 9 radiographers worked on MRI and Positron Emission Tomography (PET). 


\subsection{Investigation about Work Related Specialities}

In our self designed qestionnaire we aimed to discover how many years radiographers work in healthcare, how many hours they work per week without nightshifts and also how many nightshifts are undertaken by radiographers per month. We divided our sample according to the years spent in healthcare: $75(34.7 \%)$ respondents spent $0-5$ years; $66(30.6 \%)$ respondents spent $6-10$ years; $30(13.9 \%)$ respondents spent $11-15$ years; 19 (8.8\%) respondents spent 16-20 years and $26(12 \%)$ respondents spent 20 years in healthcare. In terms of numbers of hours worked per week we created the following classification: $16(7.4 \%)$ responents worked less than 40 hours; $162(75 \%)$ respondents worked between 40 and 50 hours and $38(17.6 \%)$ respondents worked 50 hours or more. Radiographers in our sample were diverse in the amount of nightshifts: none ( $\mathrm{n}=47)$; between 1-3 times $(\mathrm{n}=86)$; between $3-5$ times $(\mathrm{n}=73)$ and over 5 times $(\mathrm{n}=10)$. Chi-square test of association indicated no significant relationship between the years spent in healthcare and monthly nightshifts $(\mathrm{p}=0.674)$.

We wanted to find out about the continuing training habits of radiographers. Only $5.6 \%(n=12)$ of respondents said that they did not do anything in order to deepen their professional knowledge. $27.8 \%(n=60)$ periodically participate at training courses; $41.2 \%(\mathrm{n}=89)$ regularly read radiology journals to learn the latest protocols and trends. $16.2 \%(\mathrm{n}=35)$ of the surveyed radiographers constantly studied the latest procedures and protocols. Three quarters of the sample (75\%) widened their knowledge at congresses. We wanted to know how radiographers feel about the level of their professionalism. $76.9 \%(\mathrm{n}=166)$ consider their professional competence as average while $23.1 \%(\mathrm{n}=5)$ above average. It was also interesting which continuing training habit influences the subjective level of professionalism. A Chi-square test of association indicated that participating in training courses $(\mathrm{p}=0.001)$ and constant study of the latest protocols $(\mathrm{p}=0.003$ ) are associated with self-reported level of professionalism. There is no significant association between attending congresses $(\mathrm{p}=0.828)$ and the systematic study of literature $(\mathrm{p}=0.475)$ and self-reported professionalism.

\subsection{Investigation of the Relationship between the Staff and the Quality of Diagnostic Equipment}

To describe the social environment of the workplace we created the following categories: excellent ( $\mathrm{n}=23)$, good $(n=127)$, moderate $(n=60)$, bad $(n=5)$ and very bad $(n=1)$. We also described the relationship with colleagues as excellent $(n=22)$, good $(n=153)$ and average $(n=41)$. Only one-tenth of the sample experienced an excellent social environment. In proportion radiographers at the county hospitals $(n=53)$ and at the outpatient surgeries $(n=53)$ experience good social environment, radiographers working at private healthcare centers $(n=27)$ experience a good social environment as well. The majority of respondents working at university clinics $(n=43)$ experience a good social environment, and those working at national institutes experience a moderate social environment $(n=18)$. Bad or very bad social environment appears minimally among workers. Those radiographers who consider the relationship between their collegues as excellent, experience excellent social environment at their workplace. Chi-square test of association indicated a significant relationship between the social environment and between the type of the relationship among the staff $(\mathrm{p}=0.001)$.

According the last few years huge investments nation-wide into new diagnostic equipment in Hungary we asked some questions about the level of the workplaces' current diagnostic equipment. According to $28.2 \%(n=61)$ of respondents the diagnostic equipment at their workplace is at excellent level, 55,1\% $(\mathrm{n}=119)$ of respondents rated the equipment's level is good, and $15.7 \%(\mathrm{n}=34)$ of respondents rated the level of their diagnostic equipment as average. Two radiographers indicated that there was bad level of diagnostic equipments. Most places were rated to have good and average level of diagnostic equipments.

\subsection{Issues of Satisfaction of the Sample}

$17.6 \%(\mathrm{n}=38)$ of respondents are fully satisfied with their current living situation. Most of the radiographers are partially satisfied $(78.7 \%$; $n=170)$, while $3.7 \%(n=8)$ felt completely dissatisfied with their current life situation. For higher satisfaction results support and desire towards the chosen profession is essential. We were curious if radiographers in the sample would recommend to their friends radiography as a career. The majority of the sample would recommend the radiography profession $(58.3 \% ; \mathrm{n}=126)$ in spite of the difficulties and on-call workload. $25 \%(n=54)$ of respondents could not say what they would recommend to their friends at the time of completing the questionnaire and $16.7 \%(\mathrm{n}=36)$ would not recommend the radiography profession.

We asked the radiographers if they were able to go back in time of their career choice, would they choose radiography as their profession again. According to $48.1 \%(\mathrm{n}=104)$ they would be very pleased to study radiography again. Almost one third of the sample $(30.6 \% ; n=66)$ would choose other career options and $21.3 \%$ $(n=46)$ was not able to say whether they would decide on a possible re-start capability.

According to our results radiographers living with their partner and children seemed more satisfied than 
radiographers living by their own. Also, radiographers with higher educational attaintment are much more satisfied than radiographers with basic educational attaintment level. Chi-square test of association showed significant relationship between the family status $(p=0.007)$ and the educational attainment $(p=0.001)$ on the satisfactional level of the radiographers.

\subsection{Migration Intentions by Demographic Characteristics}

$30.6 \%(n=66)$ of the sample was extremely concerned about the idea of working abroad and approximately the same ratio; $29.2 \%(n=63)$ was not interested in the possibility of working abroad. However, the majority of the sample was interested about the idea of working abroad, nevertheless they have remained in Hungary due to their current living situation $(40.3 \% ; n=87)$. In terms of gender, the tendency of working abroad showed almost the same rate. From the whole male respondents $(n=69), 25(n=25)$ have already considered the idea of working abroad, and further $22(\mathrm{n}=22)$ radiographers would like to go abroad as well, but they stay in Hungary because of their living situation. The same amount of male radiographers $(n=22)$ do not consider about the possibility of workingabroad. $65(n=65)$ women of the whole female respondents $(n=147)$ stay in Hungary because of their current family status. The number of women who wish to take a chance and who would like to stay in motherland proved to be identical $(n=41 ; n=41)$. In total we can say that one third of the radiographers would like to test themselves abroad. After implementation of Chi-square test we have not found significancy between the idea of working abroad and gender $(\mathrm{p}=0.212)$.

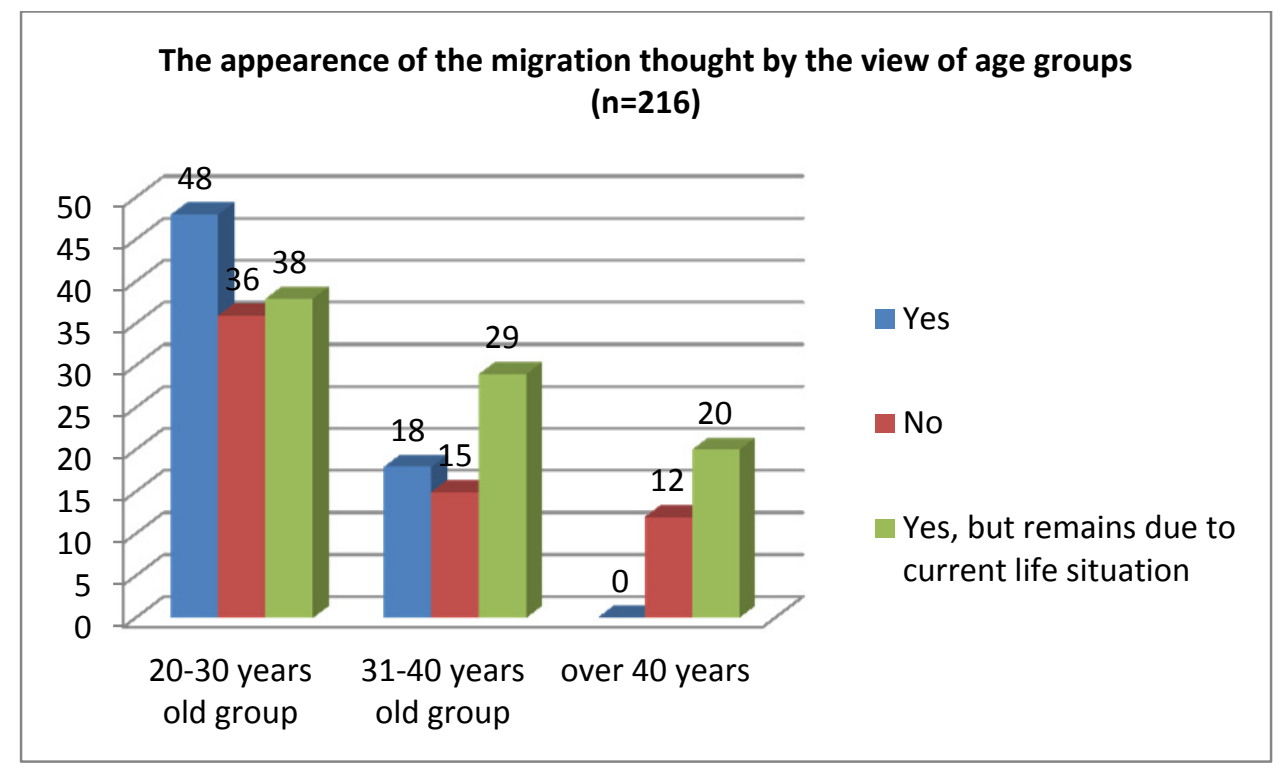

Figure 1. The appearence of the migration thought by the view of age groups

The migration thought was tipically specific among the $20-30$ years old radiographers $(n=122)$, they constituted a little more than half of the sample. The majority among the $31-40$ years old radiographers $(n=62)$ were interested in the idea of working abroad, but their current life situation prevent them from it $(\mathrm{n}=29)$. A group of radiographers who are older than 40 years considered the possibility of working abroad, but due to the current life situation remain in Hungary $(\mathrm{n}=20)$. We found a significant influence between the idea of working abroad and the age $(\mathrm{p}=0.001)$, linear regression shows a positive, moderate linear relationship $(\mathrm{r}=0.272)$ and age influences significantly on the dependent examined variable $\left(r^{2}=0.74\right)$.

The migration tendency seemed to be specific among radiographers with no children $(\mathrm{n}=54)$. Those radiographers who had children in their family $(n=43)$, most of them $(n=32)$ are also previewing their expertise abroad but due to their current living situation will stay inside borderlines. After Chi-square test we can say that there is a significant bond between the number of children in families and the tendency to migration $(\mathrm{p}=0.001)$. Surprisingly, those radiographers who are single showed the highest number of those who did not want to try their luck abroad $(n=25)$. After Chi-square statistical test we found out that the tendency of migration is not influenced by household $(\mathrm{p}=0.662)$.

We examined the possible relationship between the residence and the tendency of working abroad. According to 
the county seat occupants responses there was the lowest tendency to migration, $41(n=41)$ respondenst will stay in Hungary although this value is limited to 3 radiographers $(n=3)$ among the radiographers who work in the Capital $(n=34)$. Upon completion of Chi-square test we observed, that there is a significant influence between the residence and the thought of migration $(\mathrm{p}=0.001)$.

\subsection{Migration Tendency by the Light of Experiences Gained during Work}

75 of our respondents $(n=75)$ worked a total of 5 years in the healthcare. According to them almost the half of the group would like to test themselves in foreign country $(n=30)$. From within the group who have been working 6-10 years in healthcare $(\mathrm{n}=66)$ the majority would like to move abroad, but their current life situation prevents them $(\mathrm{n}=28)$. We can observe nearly equal proportions of distribution among workers whose are working in healthcare more than 11 years. We can say that their migration tendency is significantly influenced by the years spent in healthcare $(\mathrm{p}=0.008)$. We were interest to know what is the best additional factor contributing to migration. The level of the medical equipment at the workplaces $(\mathrm{p}=0.344)$, adventure $(\mathrm{p}=0.619)$ and existential security $(\mathrm{p}=0.070)$ does not significantly affect the tendency of migration. By contrast, the possible career advancement influences the tendency of migration significantly $(\mathrm{p}=0.001)$. From those respondents who would like to test themselves in a foreign healthcare system $(n=66) ; 93.3 \%(n=62)$ would go because of a desire for higher wages, therefore according to them we can state that higher earnings have a significant influence on the idea of working abroad $(\mathrm{p}=0.001)$.

\subsection{The Migration Tendency in the Near Future}

Our data suggested that $31.5 \%(\mathrm{n}=68)$ have already taken steps in relation to possible work opportunities abroad, while the majority of the sample $68.5 \%(\mathrm{n}=148)$ have not taken any steps. Almost half of the male respondents $(n=25)$ took steps regarding foreign employment opportunities. Most of the female respondents $(n=65)$ would like to work abroad, but because of their family status will stay in Hungary. $43(n=43)$ female respondents from the sample already took steps towards foreign relocation. After Chi-square test we can say that there was no significant relationship between gender and steps taken towards going abroad $(\mathrm{p}=0.303)$.

Table 2. The results of the respondents about taken steps towards work opportunity abroad

\begin{tabular}{|c|c|c|c|}
\hline & & \multicolumn{2}{|c|}{ Steps taken towards work opportunity abroad } \\
\hline & & Yes & No \\
\hline \multirow{2}{*}{ Sex } & Male & $11,5 \%(n=25)$ & $20,0 \%(n=43)$ \\
\hline & Female & $20,4 \%(n=44)$ & $48,1(n=104)$ \\
\hline \multirow{3}{*}{ Age } & 20-30 years old & $13,9 \%(n=30)$ & $42,6 \%(n=92)$ \\
\hline & $31-40$ years old & $11,6 \%(n=25)$ & $17,1 \%(n=37)$ \\
\hline & over 40 years & $6,0 \%(n=13)$ & $8,8 \%(\mathrm{n}=19)$ \\
\hline \multirow{3}{*}{$\begin{array}{l}\text { Current } \\
\text { financial status }\end{array}$} & Average & $16,6 \%(n=36)$ & $56,5 \%(\mathrm{n}=122)$ \\
\hline & Above average & $9,3 \%(n=20)$ & $9,3 \%(n=20)$ \\
\hline & Below average & $5,6 \%(n=12)$ & $2,7 \%(n=6)$ \\
\hline \multirow{4}{*}{ Marital status } & Living with their spouse/ life partner & $12,0 \%(\mathrm{n}=26)$ & $21,8 \%(\mathrm{n}=47)$ \\
\hline & Single & $8,8 \%(n=19)$ & $22,2 \%(n=48)$ \\
\hline & Living with their spouse/life partner and children & $8,3 \%(n=18)$ & $13,0 \%(n=28)$ \\
\hline & Living with other family member/person & $2,3 \%(n=5)$ & $11,6 \%(n=25)$ \\
\hline \multirow{4}{*}{ Inhabitancy } & County seat & $10,2 \%(n=22)$ & $41,7 \%(\mathrm{n}=90)$ \\
\hline & Town & $9,7 \%(n=21)$ & $14,8 \%(n=32)$ \\
\hline & Capital city & $11,1 \%(n=24)$ & $4,6 \%(n=10)$ \\
\hline & Village & $0,5 \%(n=1)$ & $7,4 \%(n=16)$ \\
\hline
\end{tabular}

Approximately one fourth $(n=30)$ of the group of 20-30 year old radiographers $(n=122)$ had taken steps to find job opportunities abroad. We found it interesting that the same perspective is observed at the group of 31-40; while 
among those over 40 years old, one third sought opportunities abroad. A Chi-square test indicated a significant association between age and migration intentions $(\mathrm{p}=0.046)$. Most of the respondents who lived in the capital $(n=24)$ have already taken concrete steps, therefore we can state that residence significantly influences the steps taken toward foreign job opportunity $(\mathrm{p}=0.001)$. Chi-quare test indicated no significant association with marial status ( $\mathrm{p}=0.227$ ) but we observed that of those respondents who have no children $(\mathrm{n}=142)$ nearly one third of them made steps towards possible work opportunity abroad, indicating significant association between the number of children and the steps taken $(\mathrm{p}=0.033)$. We evaluated the current financial situation in a similar view. As we mentioned earlier, most of the sample considered their financial situation as average and $27.7 \%(\mathrm{n}=36)$ had taken steps towards the direction of work opportunity abroad. $50 \%(\mathrm{n}=20)$ of the group considering their financial situation better than average, and $66.6 \%(n=12)$ of respondents considering their financial situation below average had taken steps towards work opportunity abroad. After Chi-square test we can say that there is a significant relationship between the current financial situation and taken steps towards work opportunity abroad $(\mathrm{p}=0.001)$. We estimate the number of years spent in healthcare in the same view as well. $14.6 \%$ of radiographers who are in healthcare a total of 5 years have taken steps towards abroad. The same result within the category of 6-10 years spent in healthcare was $36,36 \%$ and at the group of $11-15$ years spent in healthcare was $73.3 \% .26 .31 \%$ of the workers in healthcare working between 16-20 years and $34.61 \%$ of workers working in the segment more than 20 years have taken steps toward possible work opportunity abroad which showed to us the level of significance $(\mathrm{p}=0.001) .27$ radiographers who were working at the county hospitals and outpatient clinics have taken direct steps toward migration. Surprisingly $47.2 \%$ of radiographers who were working in private healthcare and $52 \%$ of the national institute workers had also taken steps toward the opportunity of working abroad. The Chi-square test results showed that there is a significant relation between the type of workplace and the steps taken toward migration $(\mathrm{p}=0.003$ ). The main reasons beyond the steps taken toward the possible work opportunity abroad were the lack of career advancement $(\mathrm{p}=0.001)$ and the desire for existential safety $(\mathrm{p}=0.001)$. The equipment level $(\mathrm{p}=0.678)$, adventure $(\mathrm{p}=0.785)$ and the desire for higher wages $(\mathrm{p}=0.510)$ showed no significant effect on the sample by the view of steps taken towards work opportunity abroad.

\subsection{The Responses of the Sample in View by Attrition}

$41,7 \%(\mathrm{n}=90)$ of respondents had viewed that changing their profession would be a better choice for them. $43.4 \%$ $(n=53)$ of radiographers from the group of 20-30 years old, $32.2 \%(n=20)$ of $31-40$ years olds and $53.1 \%(n=17)$ of the 40 years or older group thought that changing their current profession would be better than remaining as a radiographer. According to Chi-square test there is no significant association between the age and the will towards attrition $(\mathrm{p}=0.126)$.

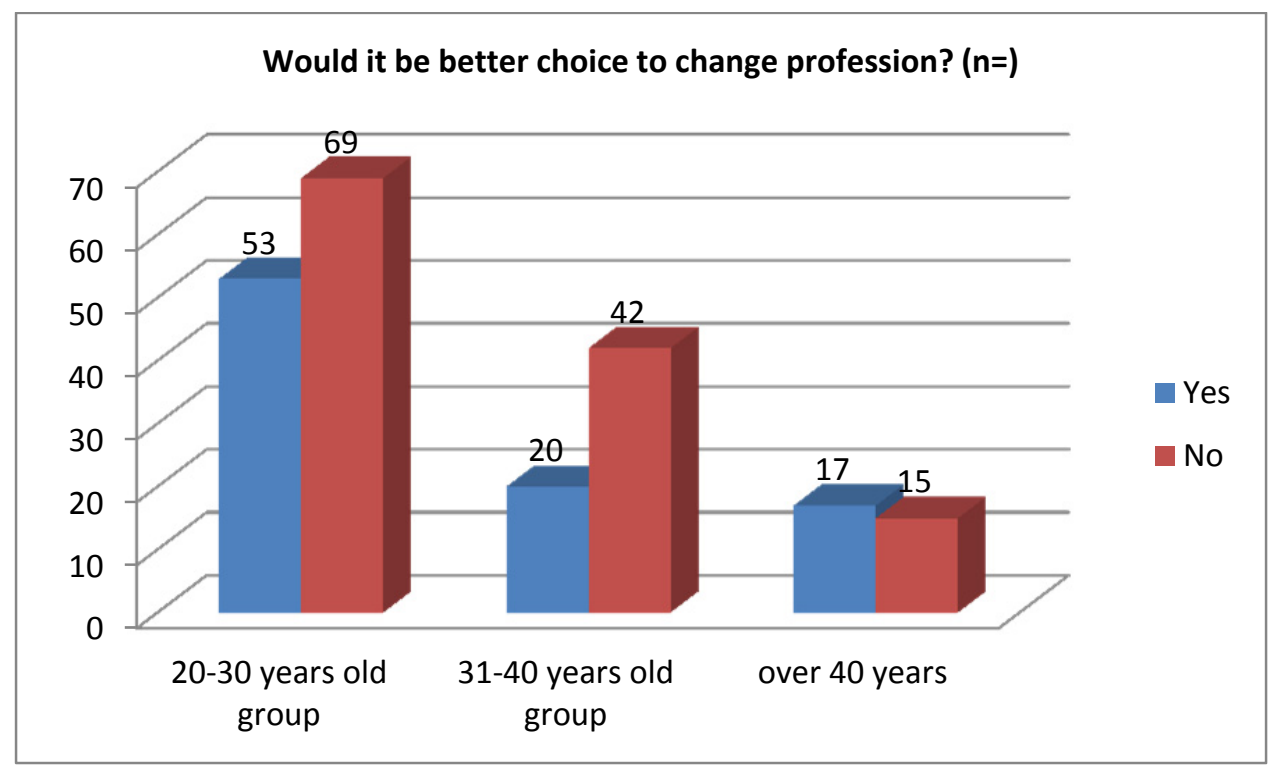

Figure 2. The rate of the attrition will by the perspective of age groups

There was no significant association with the number of children in families $(\mathrm{o}=0.456)$ or the radiographers' current financial status $(\mathrm{p}=0.364)$. It is interesting that of the single radiographers, $37(\mathrm{n}=37)$ thought that it would 
better to change profession, while $50 \%(\mathrm{n}=23)$ of radiographers who are living with their husband or partner thought that it was a good choice to be a radiographer. We observed a significant relationship between the two variables $(\mathrm{p}=0.002)$. After the application of Chi-square test we can state that there is no significant relationship between the attrition and the lack of financial recognition $(\mathrm{p}=0.161)$ and the outdated equipment of the workplaces $(\mathrm{p}=0.099)$. We found significant association with the samples' view by the lack of moral recognition $(\mathrm{p}=0.001)$ and the lack of career advancement $(\mathrm{p}=0.007)$.

\subsection{The results of the Effort Reward Imbalance Questionnaire}

The effort and the over-commitment dimension available scores ranged from 0 to 22 . The mean score in concern of the efforts were $7.71(\mathrm{SD}=3.838)$. The available scores at the reward dimension ranged from 0 to 12 and the mean score in concern of the reward was 6,18 $(\mathrm{SD}=3.383)$. The mean score for the over-commitment statement was 7.54 $(\mathrm{SD}=2.808)$ and the scores ranged from 2 to 15 . The ratio of the effort and reward scale values generated the stress value of the sample (ER). The stress values scale ranged from 0.33 to 4.00 with the mean score of 1.367 $(\mathrm{SD}=0.654)$.

Table 3. The mean results of the Effort Reward Imbalance Questionnaire

\begin{tabular}{llllll}
\hline & Number of items & Mean & SD & Minimum & Maximum \\
\hline Effort & 3 & 7,71 & 3,838 & 0 & 22 \\
Over-commitment & 6 & 7,54 & 2,808 & 2 & 15 \\
Reward & 6 & 6,18 & 3,383 & 0 & 12 \\
Stress score & Effort / Reward mean score & 1,367 & 0,654 & & \\
\hline
\end{tabular}

The mean stress score of males $(\mathrm{ER}=1.497 ; \mathrm{SD}=0.726)$ were slightly higher than female $(\mathrm{ER}=1.254 ; \mathrm{SD}=0.613)$ which showed a significant association between gender and stress score $(\mathrm{p}=0.012)$. The stress scores by view of age categories were the following: $20-30$ years old $(\mathrm{ER}=1.302 ; \mathrm{SD}=0.715), 31-40$ years old $(\mathrm{ER}=1.374 ; \mathrm{SD}=0.569)$ and older than 40 years $(\mathrm{ER}=1.356 ; \mathrm{SD}=0.611)$. After performing an ANOVA, there was not significant relationship found between the two variables $(\mathrm{p}=0,767)$. We did not find a significant relation in terms of family composition ( $\mathrm{p}=0.377$ ), nevertheless we need to mention that radiographers who lived with their husband/ partner and children had the highest stress score $(\mathrm{ER}=1.410 ; \mathrm{SD}=0.652)$. Those radiographers who do not have children had a lower stress score $(\mathrm{ER}=1.309 ; \mathrm{SD}=0.671)$ than those who had children $(\mathrm{ER}=1.453 ; \mathrm{SD}=0.596)$ but the number of children in the family did not affect significantly the stress level $(\mathrm{p}=0.538)$. We have not found a significant relationship between the education level $(\mathrm{p}=0.457)$ nor the type of the current workplace $(\mathrm{p}=0.208)$. The results showed us that those radiographers who consider their current financial situation as average had the lowest stress score $(\mathrm{ER}=1.236$; $\mathrm{SD}=0.656)$ in contrast to those who consider their current financial situation as below average ( $E R=1.595 ; \mathrm{SD}=0.801)$. After analysis of variance we can state that there is a significant relation between two variables $(\mathrm{p}=0.002)$. The lowest stress score were of those radiographers who are in healthcare for $6-$ 10 years $(\mathrm{ER}=1.197 ; \mathrm{SD}=0.540)$, while the highest stress value were found amongst the workers who spent more than 20 years in healthcare $(\mathrm{ER}=1.442 ; \mathrm{SD}=0.701)$. After the analysis of variancy we can state that there is no significant relation between the years spent in healthcare sector and stress level $(\mathrm{p}=0.401)$ neither the number of hours worked per week $(\mathrm{p}=0.757)$, nor the on-call shifts per month $(\mathrm{p}=0.502)$. According to the respondents those who were satisfied with their current living situation had lower stress level $(\mathrm{ER}=1.279 ; \mathrm{SD}=0.761)$ compaered to those who were completely dissatisfied with their life situation $(\mathrm{ER}=1.497 ; \mathrm{SD}=0.636)$, however there was no significant relation between the two variables $(\mathrm{p}=0.689)$.

\section{Discussion}

Based on our results we can say that age is significantly associated with the idea of working abroad $(\mathrm{p}=0.001)$. Radiographers between the age 20-30 years showed a higher interest in working abroad. In our opinion the main goal of freshly graduated radiographers is to achieve normal living conditions such as housing, car, increasing income. Some of the radiographers have succeeded abroad and their experience and lifestyle is spreading among the Hungarian radiographers. The majority of radiographers in our sample do not have children; this is one of the main reasons why they want to test their knowledge abroad. To strengthen this idea, those radiographers who have at least one child in the family would like to go abroad as well, but they remain because of the current family situation ( $\mathrm{p}=0.001$ ). The higher wages which can be achieved abroad are promising, but to be honest, none of the radiographers would like to leave their family home. Without any ties the person will face the fact of adventure in 
a foreign country much freer. Those radiographers who are new in the healthcare system expect much higher salary and a higher esteem. Most of our respondents are under 30 years, according to this it is evident that radiographers who spent less than 10 years in a healthcare system are more ambitious, would like to travel, gain experiences by work beyond the stateborders $(\mathrm{p}=0.001)$.

Sometimes the efforts of radiographers is not followed by esteem or a 'thank you' given by the customer or the patients. The diagnostic part of healthcare system can be characterized by a relatively high workload. The continuous pressure and the patients dissatisfaction because of the waiting time for the scans is not helping radiographers gain satisfaction and positive feedback. All these factors can lead to dissatisfaction by the side of radiographers and last but not least to attrition. In the radiographer hierarchy there is no chance to move up inside the workplace and it can be devastating to do the job round to round during decades. Maybe this is the main reason why we found significant connection between the lack of advancement $(\mathrm{p}=0.001)$ and the lack of esteem over the attrition will among Hungarian radiographers.

Prolonged stress in a workplace will decrease the radiographers motivation and will have a negative affect also on the performance. Every workplace has their own stress rate, because of that the characterization is very difficult. We must take into account that the current situation (such as examination the trauma suffered patient delivered by helicopter) can be understood and can be carried out and can be affect a different stress factor to different radiographers. This pressure can reduce by the time spent in the healt care sector. Radiographers whose are working maximum 5 years in the healthcare sector have a little bit higher stress rate, this rate will reduce in the next 6-10 years, but according to our result it will increase by the time again, showing no significancy between the two variables $(\mathrm{p}=0.401)$.

Table 4. Taken steps toward work opportunity, the change of profession and mean stress score changes by the view of years spent in healthcare system

\begin{tabular}{|c|c|c|c|c|c|c|c|c|}
\hline & & & \multicolumn{2}{|c|}{$\begin{array}{l}\text { Steps taken towards work } \\
\text { opportunity abroad }\end{array}$} & \multicolumn{2}{|c|}{$\begin{array}{l}\text { Would it be better to } \\
\text { change profession? }\end{array}$} & \multirow{2}{*}{$\begin{array}{l}\text { Mean stress } \\
\text { score }\end{array}$} & \multirow[t]{2}{*}{ Total } \\
\hline & & & yes & no & yes & no & & \\
\hline \multirow{5}{*}{$\begin{array}{l}\text { Years spent } \\
\text { healthcare } \\
\text { system }\end{array}$} & \multirow{5}{*}{ in } & $0-5$ & 11 & 64 & 37 & 38 & 1,38 & 75 \\
\hline & & $6-10$ & 21 & 45 & 22 & 44 & 1,19 & 66 \\
\hline & & $11-15$ & 22 & 8 & 9 & 21 & 1,36 & 30 \\
\hline & & $16-20$ & 5 & 14 & 7 & 12 & 1,41 & 19 \\
\hline & & $>20$ & 9 & 17 & 15 & 11 & 1,42 & 26 \\
\hline Total & & & 68 & 148 & 90 & 126 & 1,33 & 216 \\
\hline
\end{tabular}

\section{Conclusion}

Based on other results mostly the age, and the low wages are the main reasons of the migration and attrition tendency among healthcare sector workers. Our result strongly correlates with other studies, but we need to mention that correlation was difficult because very few researchers put their interest into radiology department workers, espesially into radiographers. In respect to other healthcare workers (eg.: nurses, physiotherapists) our result correlate well with the international and domestic literature so the age, the desire of higher wages and the lack of career advances seemed to be the most predispositioned factors towards carreer change and migration among Hungarian radiographers. We sincerely hope that our research will provide a solid ground for further and deeper study among the radiographers.

\section{Competing Interests Statement}

The authors declare that there no competing or potential conflicts of interest.

\section{References}

Allen, J., \& Mellor, D., (2002). Work context, personal control, and burnout amongst nurses. Western Journal of Nursing Research, 24, 905-917. https://doi.org/10.1177/019394502237701

Beitzel, K. I., Ertl, L., Grosse, C., Reiser, M., \& Ertl-Wagner, B. (2011). Job satisfaction of radiologists in Germany - status quo. Rofo, 183(8), 749-57. https://doi.org/10.1055/s-0031-1273328 
Bettina, F. P. (2006). Burnout, role conflict, job satisfaction and psychosocial health among Hungarian health care staff: A questionnaire survey. International Journal of Nursing Studies, 43, 311-318. https://doi.org/10.1016/j.ijnurstu.2005.05.003

Burisch, M. (2002). A longitudinal study of burnout: the relative importance of dispositions and experiences. Work and Stress, 16, 1-17. https://doi.org/10.1080/02678370110112506

Chang, E. M. (2006). The relationships among workplace stressors, coping methods, demographic characteristics, and health in Australian nurses. Journal of Professional Nursing, 22(1), 30-8 https://doi.org/10.1016/j.profnurs.2005.12.002

Dumont J. C. (2007). Immigrant Health workers in OECD Countries in the Broader Context of Highly-skilled Migration. In International Migration Outlook (pp.162-228).

Grönroos, E., \& Pajukari, A. (2009). Job satisfaction of the radiological department's staff. European Journal of Radiography, 1(4), 133-138. https://doi.org/10.1016/j.ejradi.2010.03.001

Kingma, M. (2001). Nursing migration: global treasure hunt or disaster-in-the-making? Nursing Inquiry, 8(4), 205-212. https://doi.org/10.1046/j.1440-1800.2001.00116.x

Kumar, R., Ahmed, J., Shaikh, B. T., Hafeez, R., \& Hafeez, A. (2013). Job satisfaction among public health professionals working in public sector: A cross sectional study from Pakistan. Human Resources for Health, 11, 2. https://doi.org/10.1186/1478-4491-11-2

Lima, F. E., Jorge, M. S., \& Moreira, T. M. (2006). Hospital humanization: professional satisfaction in a pediatric hospital. Rev Bras Enferm, 59(3), 291-296. https://doi.org/10.1590/S0034-71672006000300008

Lok, P., \& Crawford, J. (2003). The effect of organizational culture and leadership style on job satisfaction and organizational commitment. Journal of Management Development, 23, 321-38 https://doi.org/10.1108/02621710410529785

Lowe, M., \& Duang-Rung, C. (2016). Factors influencing the migration of West African health professionals. The Pan African Medical Journal, 24, 237. https://doi.org/10.11604/pamj.2016.24.237.9402

Makowiec-Dabrowska, Koszada-Wlodarczyk, W., Bortkiewicz, A, Gadzicka, E., Siedlecka, J., Józwiak, Z., \& Pokorski, J. (2008). Occupational and non-occupational determinants of work ability. Medycyna pracy, 59(1), 9-24.

Mosadeghrad, A. M., Ferlie, E., \& Rosenberg, D. (2011). A study of relationship between job stress, qulity of wotking life and turnover intention among hospital employees. Health Service Management Research, 24(4),170-81. https://doi.org/10.1258/hsmr.2011.011009

Ross, S. J., Polsky, D., \& Sochalski, J. (2005). Nursing shortages and international nurse migration, International Nursing Review, 52(4), 253-265. https://doi.org/10.1111/j.1466-7657.2005.00430.x

Smith, S. C. (2002). Happiness at work: It's an inside job! Insight, 27(1), 3-4.

Suciu, Ş. M., Popescu, C. A., Ciumageanu, M. D., \& Buzoianu, A. D. (2017). Physician migration at its roots: a study on the emigration preferences and plans among medical students in Romania, Hum Resour Health, 19,15(1), 6. https://doi.org/10.1186/s12960-017-0181-8

von Vultee, P. J., Axelsson, R., \& Arnetz, B. (2007). The impact of organisational settings on physician wellbeing. Int J Health Care Qual Assur, 20(6), 506-515. https://doi.org/10.1108/09526860710819440

\section{Copyrights}

Copyright for this article is retained by the author(s), with first publication rights granted to the journal.

This is an open-access article distributed under the terms and conditions of the Creative Commons Attribution license (http://creativecommons.org/licenses/by/4.0/). 